\title{
Fatty Acid Compositions of the Lipids Obtained from Commercial Salmon Products
}

\author{
Toru Ota,* Shigefumi Sasaki,* Tsutomu Abe, ${ }^{*}$ \\ and Toru Takagi*
}

(Received September 25, 1989)

\begin{abstract}
The fatty acid compositions of total lipids from the raw fillets of four species of salmons, the salted fillet and the canned fillets from sockeye salmon were investigated with open-tubular gasliquid chromatography. The major components of fatty acids of the present samples were similar to those of masu salmon, pink salmon and chum salmon studied previously. Each sample showed the characteristic pattern of the fatty acids. Food products of sockeye salmon have high contents of 20: $1(n-11)$ and $22: 1(n-11$ and $n-13)$. The raw fillet of coho salmon has higher contents of polyunsaturated fatty acids than other samples. Moreover, the contents of $18: 2$ (n-6) in the raw fillets of rainbow trout and chinook salmon were apparently higher than those of other fish studied. It was inferred that these characters of fatty acid compositions were influenced by the fatty acid patterns of dietary lipids.
\end{abstract}

Salmons are representative edible fish in Japan, and eaten in various forms (raw, salted, canned and smoked, etc.). Recently, salmon culture industry becomes active, and cultured salmon as well as wild salmon are eaten. Moreover, a large quantity of salmon is imported from foreign countries (USA, Canada, Norway, Chile, New Zealand, Australia, etc.). Therefore, it is assumed that the lipids of commercial salmon products have variable properties according to the fishing area, the culture condition and the species of salmon.

It is known that fish lipids are rich in $n-3$ polyunsaturated fatty acids (PUFA) which are epidemiologically important substances. ${ }^{2}$ Dietary consumption of fish lipids containing $n-3$ PUFA such as eicosapentaenoic acid and docosahexaenoic acid was found to change the fatty acid compositions of total cardiac lipid. ${ }^{2-4}$ Many studies emphasized the importance of ingesting fish oil and fish products. ${ }^{5}$ )

There are some reports on the fatty acid compositions of the lipids from salmons. ${ }^{6-11}$ The fatty acid compositions of the lipids from masu samlon, pink salmon and chum salmon were elucidated in detail by using open-tubular gasliquid chromatography (GLC) in our laboratory. ${ }^{12,13)}$

The purpose of the present study was to investigate fatty acids of the lipids obtained from the raw fillets of four species of salmons, the salted fillet and the canned fillets from sockeye salmon, and to indicate significant differences in the fatty acid compositions of commercial products from salmons.

\section{Materials and Methods}

\section{Materials}

The raw fillets of four species of salmons, the salted fillet and the canned fillets from sockeye salmon were bought at food markets in Hakodate. The characteristics of samples are shown in Table 1.

Lipid Extraction and Preparation of Fatty Acid Methyl Esters (FAME)

Total lipids (TL) were extracted from 2-4 fillets (200-500 g) by the method of Bligh and Dyer. ${ }^{14)}$

Preparations and purifications of FAME were carried out as described previously. ${ }^{155}$

\section{Analysis of Lipid Class Composition}

The analysis of lipid class compositions of $\mathrm{TL}$ was carried out using thin-layer chromatographyflame ionization detector system (TLC-FID) (Iatron Laboratories, Tokyo) as described previously. ${ }^{16)}$ The rods used were Chromarods-SII. The rods were scaned through the Iatroscan FID immediately before applying the lipid samples. The chloroform solutions of lipids were prepared

* Faculty of Fisheries, Hokkaido University, Hakodate 041, Japan（太田真，佳々九茂文，阿部茂， 高木 徹: 北海道大学水産学部). 
Table 1. Characteristics of samples

\begin{tabular}{lllll}
\hline $\begin{array}{c}\text { Common name } \\
\text { (Scientific name) }\end{array}$ & Form & Habitat & \multicolumn{1}{c}{$\begin{array}{c}\text { Place of production } \\
\text { or producer }\end{array}$} & $\begin{array}{c}\text { Date of purchase } \\
\text { or production }\end{array}$ \\
\hline $\begin{array}{c}\text { Rainbow trout } \\
\text { (Salmo gairdneri) }\end{array}$ & raw & cultured & New Zealand & April 13, 1989. \\
$\begin{array}{c}\text { Chinook salmon } \\
\quad \text { (Oncorhynchus tshawytscha) }\end{array}$ & raw & cultured & Scotland in England & April 13, 1989. \\
$\begin{array}{c}\text { Coho salmon } \\
\text { (Oncorhynchus kisutch) }\end{array}$ & raw & cultured & Miyagi prefecture in Japan & April 28, 1989. \\
$\begin{array}{c}\text { Sockeye salmon } \\
\text { (Oncorhynchus nerka) })\end{array}$ & raw & wild & Northern Pacific Ocean & April 30, 1989. \\
& canned A & wild & Northern Pacific Ocean & May 22, 1989. \\
& canned B & - & $\begin{array}{l}\text { Nichiro Gyogyo kaisha, Ltd. } \\
\text { Kyokuyo Co., Ltd. }\end{array}$ & $\begin{array}{l}\text { Dec. 15, 1988. } \\
\text { Summer, 1988. }\end{array}$ \\
\hline
\end{tabular}

Table 2. Lipid contents and lipid class compositions of the lipids from samples*

\begin{tabular}{llrrrrrrr}
\multicolumn{1}{c}{ Fish } & \multirow{2}{*}{ Form } & TL & \multicolumn{5}{c}{ Lipid (\% in TL) } \\
& & & HC+SE & TG & FFA & ST & PL \\
\hline Rainbow trout & raw & 17.3 & 1.3 & 91.9 & 0.1 & 0.3 & 6.4 \\
Chinook salmon & raw & 8.7 & 2.0 & 86.5 & 0.1 & 0.9 & 10.5 \\
Coho salmon & raw & 18.1 & 2.2 & 89.9 & - & 2.3 & 5.6 \\
Sockeye & raw & 9.8 & 1.0 & 87.0 & 0.6 & $\mathbf{0 . 4}$ & 11.0 \\
salmon & salted & 5.7 & 0.4 & 76.2 & 8.3 & 0.6 & 14.5 \\
& canned A & 8.1 & 0.3 & 88.6 & 1.4 & $\mathbf{0 . 1}$ & 9.6 \\
& canned B & 6.8 & 1.8 & 86.2 & - & $\mathbf{0 . 7}$ & 11.3 \\
\hline
\end{tabular}

* TL, Total lipids; HC +SE, Hydrocarbons +Sterol esters; TG, Triacylglycerols; FFA, Free fatty acids; ST, Free sterols; PL, Polar lipids.

in the concentration between 10 to $15 \mu \mathrm{g} / \mu \mathrm{l}$. The chloroform solutions were spotted on the rods in the $1 \mu \mathrm{l}$ size with a single spotting action using Drummond Microcap disposable pipets (Drummond Scientific Co., USA). The rods, after spotting, were developed with a developing solvent for a distance of $10 \mathrm{~cm}$ from the origin. The developing solvent was $n$-hexane/diethyl ether/formic acid $(90: 10: 0.2, \mathrm{v} / \mathrm{v})$. The rods were then scanned on the Iatroscan TH-10 (Iatron Laboratories, Tokyo). The scan speed was set at $30 \mathrm{sec} / \mathrm{scan}$. Peak area percentages and retention data were obtained by a Shimadzu integrator C-R1A (Shimadzu Seisakusho Co., Kyoto). Each peak on the chromatograms was identified on the basis of the agreement with the retention data with those of the standard mixtures I and II prepared in our laboratory. The standard mixture I contained triacylglycerols, cholesterol and free fatty acids in the weight ratios of $52: 43: 10$, respectively. The ratios of hydrocarbon + sterol esters, triacylglycerols, free fatty acids and free sterols in the standard mixture II were $15: 30: 5: 50$, respectively.

\section{Open-tubular GLC}

Open-tubular GLC of FAME was carried out with a Shimadzu GC-6AM (Shimadzu Seisakusho Co., Kyoto) equipped with FID. The metal wall open-tubular column used was $50 \mathrm{~m}$ in length and $0.25 \mathrm{~mm}$ i.d., coated with Silar 5CP. The column temperature was $190^{\circ} \mathrm{C}$. The detector and injector were held at $230^{\circ} \mathrm{C}$. The carrier gas was $\mathrm{H}_{2}$. Peak area percentages were obtained with a Shimadzu integrator C-R6A (Shimadzu Seisakusho Co., Kyoto). Each peak on the gas chromatogram was identified as described previously. ${ }^{15)}$

\section{Results and Discussion}

\section{Lipid Contents and Lipid Class Compositions}

Table 2 shows lipid contents and lipid class compositions of TL. The raw fillets of rainbow trout $(17.3 \%)$ and coho salmon $(18.1 \%)$ have much higher lipid contents than those of chinook salmon $(8.7 \%)$ and sockeye salmon $(9.8 \%)$. The lipid contents of the flesh from masu salmon, pink salmon and chum salmon were $6.8 \%, 9.7 \%$ and $5.0 \%$, respectively. ${ }^{2},{ }^{13}$ ) Salmons usually have seasonal cycles of lipid content associated with migration and spawning. ${ }^{17)}$ Yamaguchi et al. reported that the flesh of cultured coho salmon had higher lipid content than that of wild fish. ${ }^{103}$ 
Table 3. Fatty acid compositions of the lipids from samples $(w \mathrm{t} \%)^{*}$

\begin{tabular}{|c|c|c|c|c|c|c|c|c|c|}
\hline \multirow{3}{*}{$\begin{array}{l}\text { Peak } \\
\text { No. }\end{array}$} & \multirow{3}{*}{ Fatty acid } & \multirow{3}{*}{ RRT } & \multirow{3}{*}{$\begin{array}{c}\text { Rainbow } \\
\text { trout } \\
\text { raw }\end{array}$} & \multirow{3}{*}{$\begin{array}{c}\text { Chinook } \\
\text { salmon } \\
\text { raw }\end{array}$} & \multirow{3}{*}{$\begin{array}{l}\text { Coho } \\
\text { salmon } \\
\text { raw }\end{array}$} & \multicolumn{4}{|c|}{ Sockeye salmon } \\
\hline & & & & & & \multirow{2}{*}{ raw } & \multirow{2}{*}{ salted } & \multicolumn{2}{|c|}{ canned } \\
\hline & & & & & & & & A & B \\
\hline 1 & $12: 0$ & 0.133 & 0.07 & 0.10 & 0.14 & 0.05 & 0.00 & 0.04 & 0.05 \\
\hline 2 & $13: 0$ & 0.187 & 0.03 & 0.04 & 0.03 & 0.02 & 0.03 & 0.02 & 0.03 \\
\hline 3 & iso-14:0 0 & 0.223 & 0.03 & 0.02 & 0.03 & 0.02 & 0.02 & 0.02 & 0.02 \\
\hline 4 & $14: 0$ & 0.263 & 5.16 & 4.77 & 5.61 & 5.08 & 5.06 & 5.41 & 3.80 \\
\hline 5 & $4,8,12-\mathrm{TMTD}$ & 0.273 & 0.11 & 0.14 & 0.12 & 0.08 & 0.06 & 0.08 & 0.08 \\
\hline 6 & $14: 1 \mathrm{n}-7$ & 0.283 & 0.07 & 0.05 & 0.04 & 0.04 & 0.04 & 0.04 & 0.03 \\
\hline 7 & $14: 1 n-5$ & 0.298 & 0.04 & 0.03 & 0.06 & 0.03 & 0.03 & 0.03 & 0.02 \\
\hline 8 & iso-15: 0 & 0.312 & 0.29 & 0.23 & 0.26 & 0.22 & 0.20 & 0.20 & 0.20 \\
\hline 9 & anteiso-15:0 & 0.331 & 0.07 & 0.06 & 0.08 & 0.08 & 0.07 & 0.07 & 0.09 \\
\hline 10 & $15: 0$ & 0.367 & 0.35 & 0.37 & 0.45 & 0.34 & 0.40 & 0.38 & 0.42 \\
\hline 11 & iso-16: 0 & 0.436 & 0.07 & 0.08 & 0.08 & 0.07 & 0.07 & 0.06 & 0.09 \\
\hline 12 & Pristanic & 0.485 & 0.01 & 0.02 & 0.02 & 0.12 & 0.06 & 0.11 & 0.08 \\
\hline 13 & $16: 0$ & 0.520 & 17.25 & 16.35 & 17.59 & 12.63 & 13.86 & 14.81 & 13.46 \\
\hline 14 & $16: 1 n-11$ & 0.561 & 0.23 & 0.28 & 0.41 & 0.32 & 0.35 & 0.29 & 0.40 \\
\hline 15 & $16: 1 n-9$ & 0.571 & 0.29 & 0.29 & 0.30 & 0.16 & 0.25 & 0.20 & 0.24 \\
\hline 16 & $16: 1 n-7$ & 0.589 & 7.58 & 5.86 & 5.54 & 3.97 & 3.18 & 3.17 & 3.06 \\
\hline 17 & iso-17:0 & 0.608 & 0.37 & 0.33 & 0.43 & 0.43 & 0.47 & 0.46 & 0.47 \\
\hline 18 & anteiso-17:0 & 0.646 & 0.08 & 0.08 & 0.10 & 0.08 & 0.07 & 0.07 & 0.08 \\
\hline 19 & $16: 2 n-4$ & 0.705 & 0.21 & 0.24 & 0.36 & 0.27 & 0.26 & 0.29 & 0.35 \\
\hline 20 & $17: 0$ & 0.715 & - & - & 0.36 & 0.85 & 0.39 & 0.62 & 0.54 \\
\hline 21 & $16: 3 n-4$ & 0.806 & 0.35 & 0.37 & 0.49 & 0.24 & 0.28 & 0.25 & 0.28 \\
\hline 22 & $16: 4 n-1$ & 0.946 & 0.22 & 0.15 & 0.36 & 0.12 & 0.08 & 0.07 & 0.03 \\
\hline 23 & 18:0 & 1.000 & 3.15 & 3.70 & 3.76 & 2.45 & 2.51 & 2.73 & 2.94 \\
\hline 24 & $18: 1 n-11$ & 1.093 & 1.46 & 1.04 & 0.67 & 1.30 & 1.34 & 1.24 & 0.82 \\
\hline 25 & $18: 1 \mathrm{n}-9$ & 1.125 & 15.22 & 17.32 & 14.21 & 10.13 & 10.45 & 9.65 & 15.26 \\
\hline 26 & $18: 1 \mathrm{n}-7$ & 1.143 & 2.73 & 3.07 & 3.52 & 2.02 & 1.86 & 1.70 & 1.81 \\
\hline 27 & $18: 1 n-5$ & 1.179 & 0.41 & 0.30 & 0.43 & 0.80 & 0.84 & 0.84 & 0.94 \\
\hline 28 & $18: 2 n-9$ & 1. 281 & 0.06 & 0.04 & 0.05 & 0.04 & 0.03 & 0.02 & 0.03 \\
\hline 29 & $18: 2 n-6$ & 1.320 & 4.22 & 5.06 & 2.49 & 1.27 & 1.56 & 1.52 & 1.49 \\
\hline 30 & $18: 3 n-6$ & 1.382 & 0.11 & 0.10 & - & 0.21 & 0.58 & 0.41 & 0.38 \\
\hline 31 & $19: 1 \mathrm{a}-8$ & 1.553 & 0.17 & 0.16 & 0.24 & 0.06 & 0.12 & 0.11 & 0.09 \\
\hline 32 & $18: 3 n-3$ & 1.612 & 1.11 & 1.19 & 0.94 & 0.66 & 1.30 & 1.05 & 0.93 \\
\hline 33 & $18: 4 n-3$ & 1.781 & 1.60 & 1.25 & 1.46 & 0.95 & 1.83 & 1.57 & 1.15 \\
\hline 34 & $18: 4 n-1$ & 1.818 & 0.27 & 0.18 & 0.31 & 0.15 & 0.09 & 0.10 & 0.05 \\
\hline 35 & $20: 0$ & 1.917 & 0.10 & 0.14 & 0.10 & 0.18 & 0.14 & 0.18 & 0.12 \\
\hline 36 & $20: 1 \mathrm{n}-11$ & 2.094 & 1.10 & 0.95 & 2.51 & 14.46 & 12.31 & 14.12 & 9.60 \\
\hline 37 & $20: 1 \mathrm{n}-9$ & 2.138 & 6.97 & 5.93 & 1.92 & 4.02 & 2.97 & 3.21 & 2.74 \\
\hline 38 & $20: 1 \mathrm{n}-7$ & 2.181 & 0.32 & 0.34 & 0.19 & 0.44 & 0.25 & 0.32 & 0.34 \\
\hline 39 & $5,11-20: 2$ & 2.264 & 0.04 & 0.04 & 0.05 & 0.17 & 0.11 & 0.15 & 0.15 \\
\hline 40 & $20: 2 n-6$ & 2.514 & 0.33 & 0.44 & 0.28 & 0.36 & 0.40 & 0.43 & 0.42 \\
\hline 41 & $20: 4 n-6$ & 2.931 & 0.23 & 0.52 & 0.95 & 0.33 & 0.37 & 0.41 & 0.48 \\
\hline 42 & $20: 3 n-3$ & 3.079 & 0.13 & 0.16 & 0.15 & 0.17 & 0.25 & 0.25 & 0.24 \\
\hline 43 & $20: 4 n-3$ & 3.387 & 1.08 & 1.11 & 1.44 & 0.90 & 1.33 & 1.11 & 1.17 \\
\hline 44 & $20: 5 \mathrm{n}-3$ & 3.599 & 4.76 & 4.58 & 8.14 & 6.65 & 7.07 & 6.87 & 6.88 \\
\hline 45 & $22: 1 \mathrm{n}-11, \mathrm{n}-13$ & 4.002 & 6.60 & 6.57 & 2.21 & 11.56 & 8.04 & 8.88 & 6.75 \\
\hline 46 & $22: 1 \mathrm{n}-9$ & 4.055 & 0.93 & 0.90 & 0.36 & 1.02 & 0.60 & 0.69 & 1.15 \\
\hline 47 & $22: 1 \mathrm{n}-7$ & 4.165 & 0.11 & 0.09 & 0.06 & 0.15 & 0.08 & 0.10 & 0.11 \\
\hline 48 & $21: 5 n-3$ & 5.550 & - & 0.05 & - & - & - & - & 0.03 \\
\hline 49 & $22: 4 n-6$ & 5.992 & 0.08 & 0.20 & 0.24 & 0.10 & 0.16 & 0.11 & 0.23 \\
\hline 50 & $22: 5 n-6$ & 6.392 & 0.06 & 0.07 & 0.07 & 0.05 & 0.06 & 0.05 & 0.06 \\
\hline 51 & $22: 5 \mathrm{n}-3$ & 6.966 & 1.56 & 1.96 & 3.22 & 1.83 & 1.98 & 1.34 & 1.81 \\
\hline 52 & $22: 6 n-3$ & 7.389 & 8.71 & 8.75 & 12.50 & 7.80 & 11.97 & 10.36 & 13.73 \\
\hline 53 & $24: 1 n-9$ & 7.674 & 0.51 & 0.79 & 0.72 & 0.93 & 0.71 & 0.80 & 1.15 \\
\hline \multicolumn{2}{|c|}{ Others } & & 2.99 & 3.14 & 3.95 & 3.62 & 3.46 & 2.99 & 3.13 \\
\hline \multicolumn{2}{|c|}{ Total Sat. } & & 27.14 & 26.43 & 29.16 & 22.71 & 23.41 & 25.26 & 22.47 \\
\hline \multirow{2}{*}{\multicolumn{2}{|c|}{$\begin{array}{l}\text { Total Mono. } \\
\text { Total PUFA }\end{array}$}} & & 44.74 & 43.97 & 33.39 & 51.41 & 43.42 & 45.39 & 44.51 \\
\hline & & & 25.13 & 26.46 & 33.50 & 22.27 & 29.71 & 26.36 & 29.89 \\
\hline \multicolumn{2}{|c|}{$n-3 / n-6$ ratio } & & 3.77 & 2.96 & 6.91 & 8.17 & 8.22 & 7.70 & 8.48 \\
\hline
\end{tabular}

* RRT, Relative retention time; 4, 8, 12-TMTD, 4, 8, 12-Trimethyltridecanoic acid; Pristanic, 2, 6, 10, 14-Tetramethylpentadecanoic acid; Sat., Saturated fatty acids; Mono., Monounsaturated fatty acids; PUFA, Polyunsaturated fatty acids; n-3, Fatty acids having n-3 structure; n-6, Fatty acids having n-6 structure. 
The lipid contents of the salted fillet and the canned fillets from sockeye salmon ranged from $5.7 \%$ to $8.1 \%$. There were no significant differences in lipid contents of food products from sockeye salmon.

More than $85 \%$ of TL were triacylglycerols and the remainder were mostly polar lipids in other fillet samples except for the saited fillet from sockeye salmon. Although free fatty acids (FFA) could not be detected in all the samples except for the salted fillet from sockeye salmon, FFA in the salted fillet from sockeye salmon made up $8.3 \%$ of TL. FFA in the salted fillet from sockeye salmon was caused by the hydrolysis of esterified fatty acids by the activity of the enzyme.

\section{Major Fatty Acid Components}

Table 3 shows the fatty acid compositions of the lipids of samples. The major components were $14: 0,16: 0,16: 1(n-7), 18: 0,18: 1(n-9)$, $18: 1(\mathrm{n}-7), 18: 2(\mathrm{n}-6), 20: 1(\mathrm{n}-11), 20: 1(\mathrm{n}-9)$, $20: 5(n-3), 22: 1(n-11$ and $n-13), 22: 5(n-3)$ and 22: $6(n-3)$. These components were detected at the level above $3 \%$ of the total fatty acids in one or more samples. The total contents of major components were more than $80 \%$ in all samples. These major components were similar to those of masu salmon, pink salmon and chum salmon. ${ }^{12,13)}$

\section{Saturated Fatty Acids}

The total saturated acids were $20-30 \%$ of total fatty acids in all samples. The most predominant saturated acid was 16:0, followed by $14: 0$ and then 18:0. Although branched-chain fatty acids and odd numbered fatty acids were also detected, the proportions of these fatty acids were less than $1.0 \%$ of total fatty acids.

\section{Monounsaturated Fatty Acids}

The total monounsaturated fatty acids exceeded $40 \%$ of total fatty acids in all the samples except for the raw fillet of coho salmon $(33.39 \%)$. Especially, an half of total fatty acids were monounsaturated fatty acids in the raw fillet of sockeye salmon. While there were no significant differences in the contents of other monounsaturated fatty acids, the raw fillet and food products from sockeye salmon have much higher contents of 20: $1(n-11)$ and $22: 1(n-11$ and $n-13)$ than those of other species. It was reported that the contents of 20: $1(\mathbf{n}-11)$ in masu salmon, pink salmon and chum salmon were $4.61 \%, 0.87 \%$ and $7.47 \%$ of total fatty acids, and the contents of $22: 1(\mathrm{n}-11$ and $n-13$ ) were $2.93 \%, 1.03 \%$ and $5.83 \%$, respectively. ${ }^{12,13)}$ Yamada and Hayasai reported that the contents of $20: 1$ and $22: 1$ in sockeye salmon were $17.0 \%$ and $10.3 \%$ of total fatty acids. ${ }^{18)}$ It is known that food habits of salmon are variable according to the species. ${ }^{10)}$ The main diets of sockeye salmon are copepods, euphausiids, amphipods and squid in which their lipids are rich in the wax esters. ${ }^{20)}$ The major fatty alcohols of the wax esters in their lipids are alc 20:1 and alc $22: 1 .{ }^{21,22)}$ Therefore, it was assumed that the lipids of sockeye salmon were rich in 20:1 (n-11) and 22:1 (n-11 and n-13). This character of sockeye salmon lipids may be due to their diet lipids.

\section{PUFA}

The total PUFA were less than $30 \%$ of total fatty acids in all the samples except for the raw fillet of coho salmon $(33.50 \%)$. The major PUFA of samples were $20: 5(n-3)(4.58-8.14 \%)$ and $22: 6(n-3)(7.80-13.73 \%)$. The former is precursor of eicosanoids (prostaglandins and leukotrienes), and their biological activities have been noticeable in biochemistry and pharmacology. The raw fillet of coho salmon has higher contents of 20: $4(n-6), 20: 5(n-3), 22: 5(n-3)$ and 22: $6(n-3)$ than other samples. Yamaguchi et al. reported that the fatty acid composition of the lipids in cultured coho salmon were influenced by the patterns of fatty acids in their dietary lipid. ${ }^{10)}$ Their principal diets were mackerel and sardine in which their lipids were rich in PUFA. It was reported the contents of PUFA were $30-40 \%$ of total fatty acids in the sardine and mackerel. ${ }^{23,24}$ The most of PUFA in these fishes comprised $20: 5(n-3)$ and $22: 6(n-3)$. The proportions of $18: 2(n-6)$ in the raw fillets of rainbow trout and chinook salmon were $4.22 \%$ and $5.06 \%$, and were higher than those of coho salmon (2.49\%) and sockeye salmon $(1.27-1.56 \%)$. Suzuki et al. reported that the muscle lipids of cultured rainbow trout contained higher percentages of $18: 2(n-6)$ than those of wild fish. ${ }^{25)}$ They indicated that the amount of $18: 2(n-6)$ of dorsal muscle lipids depended on the diet lipids. The contents of $18: 2(\mathrm{n}-6)$ in masu salmon, pink salmon and chum salmon were less than $1 \%$ of total fatty acids. ${ }^{12,13}$ It was inferred that these characters of fatty acid compositions were influenced by the fatty acid patterns of dietary lipids. The ratios of $n-3$ to $n-6$ PUFA ranged from 6.91 to 8.48 in other samples except 
for rainbow trout (3.77) and chinook salmon (2.96). This ratio was markedly influenced by the content of $18: 2(n-6)$.

\section{Acknowledgement}

The authors wish to thank Professor Tatsuaki Maeda, Faculty of Fisheries, Hokkaido University, for his helpful advice on food habits of salmons.

\section{References}

1) R. G. Ackman: in "Nutritional Evaluation of Long-Chain Fatty Acid in Fish Oil" (ed. by S. M. Barlow and M.E. Stansby), Academic Press, New York, 1982, pp. 25-88.

2) B. Teige and J. L. Beare-Rogers: Lipids, 8, 584-587 (1973).

3) S. Gudbjarnason and G. Oskarsdotler: Biochim. Biophys. Acta., 487, 10-15 (1977).

4) J. Opstvedt, H. Svaar, P. Hansen, J. Pettersen, F. T. Langmark, S. M. Barlow, and I. F. Duthie: Lipids, 14, 356-371 (1979).

5) G. J. Nelson and R. G. Ackman: Lipids, 23, 1005-1014 (1988).

6) T. Ota, T. Takagi, and T. Terao: Bull. Fac. Fish. Hokkaido Univ., 29, 155-163 (1973).

7) H. Kusaka, M. Takigawa, T. Tsubouchi, S. Ohta, and S. Kamimura: Yukagaku, 34, 288293 (1985).

8) H. Kusaka, M. Takigawa, T. Tsubouchi, and S. Ohta: Yukagaku, 34, 294-295 (1985).

9) S. Ando, M. Hatano, and K. Zama: Nippon Suisan Gakkaishi, 51, 1817-1824 (1985).

10) T. Yamaguchi, Y. Sato, M. Ito, N. Moritani, and M. Hata: Nippon Suisan Gakkaishi, 54, $1601-1605$ (1988).

11) R. V. Golovnya, T. E. Kuz'menko, V. P. Uralets, and A. L. Samusenko: Prikl. Biokhim. Mikrobiol., 14, 609-614 (1978).

12) S. Sasaki, T. Ota, and T. Takagi: Nippon Suisan Gakkaishi, 59, 1655-1660 (1989).

13) S. Sasaki, T. Ota, and T. Takagi: Nippon Suisan Gakkaishi, 55, 2191-2197 (1989).

14) E. G. Bligh and W.J. Dyer: Can. J. Biochem. Physiol., 37, 911-917 (1959).

15) M. Kaneniwa, $Y$. Itabashi, and T. Takagi: Nippon Suisan Gakkaishi, 53, 861-866 (1987).

16) T. Onshima, W. M. N. Ratnayake, and R. G. Ackman: J. Am. Oil. Chem. Soc., 64, 219-223 (1987).

17) R. G. Ackman and C. McLeod: Can Inst. Food. Sci. Techol. J., 21, 390-398 (1988).

18) M. Yamada and K. Hayashi: Nippon Suisan Gakkaishi, 41, 1143-1152 (1975).

19) B. J. Lebrasseur: J. Fish. Res. Bd. Canada, 23, 85-100 (1966).

20) M. Ueno: Nippon Suisan Gakkaishi, 34, 315318 (1968).

21) H. Takahashi and M. Yamada: Nippon Suisan Gakkaishi, 42, 769-776 (1976).

22) W. N. Ratnayake and R. G. Ackman: Lipids, 14, 795-803 (1979).

23) Y. Itabashi and T. Takagi: Yukagaku, 29, 855865 (1980).

24) M. Ohtsuru, M. Fujii, M. Ishinaga, and M. Kito: Nippon Nogeikagaku Kaishi, 58, 35-42 (1984).

25) H. Suzuki, K. Okazaki, S. Hayakawa, S. Wada, and S. Tamura: J. Agric. Food Chem., 34, $58-60(1986)$. 